\title{
Evaluating Material Properties to Optimize Wood Strands for Wind Erosion Control
}

\section{N.S. Copeland}

Washington State University, Pullman, WA 99164, ncopeland@wsu.edu.

\section{B.S. Sharratt}

USDA Agricultural Research Service, Pullman, WA 99164, sharratt@wsu.edu.

\section{R.B. Foltz}

USDA Forest Service - Rocky Mountain Research Station, Moscow, ID 83843, rfoltz@fs.fed.us.

\section{J.Q. Wu}

Washington State University, Pullman, WA 99164, jwu@wsu.edu.

\section{J.H. Dooley}

Forest Concepts, LLC, Auburn, WA 98001, jdooley@seanet.com

\author{
Written for presentation at the \\ 2006 ASABE Annual International Meeting \\ Sponsored by ASABE \\ Portland Convention Center \\ Portland, Oregon \\ 9 - 12 July 2006
}

\begin{abstract}
Wind erosion is a widespread problem in much of the western United States due to arid conditions and persistent winds. Fugitive dust from eroding land poses a risk to both environmental quality and human health. Since the advent of the Clean Air Act in 1971, ambient air quality standards have been set regulating particulate matter in the atmosphere. Agricultural straw has been widely used for erosion control, but there are numerous drawbacks to its use. In addition to the fact that it is a lightweight material and lacks stability during high wind events, there is growing concern over the introduction of noxious weeds to wildlands, chemical residues from pesticides, and risks associated with dust particles liberated from the shattering of straw elements during the


application process. The efficacy of a wood strand material, a wood analog to straw, for wind erosion mitigation was investigated during this study. A series of wind tunnel tests were conducted to evaluate material properties of wood strands in terms of reducing total sediment loss and maintaining air quality. Results indicate that wood strands are stable at wind speeds of up to $18 \mathrm{~m} / \mathrm{s}$, while wheat straw is only stable at wind speeds of up to $6.5 \mathrm{~m} / \mathrm{s}$. At a wind velocity of $18 \mathrm{~m} / \mathrm{s}$, the straw, due to its instability, did not reduce soil loss; however, wood strands reduced total sediment loss and peak dust emissions by over $90 \%$ when compared to a bare soil.

Keywords. Wind erosion, Erosion control, Wind tunnel, Wood strands, $\mathrm{PM}_{10}$ emissions, Air quality.

The authors are solely responsible for the content of this technical presentation. The technical presentation does not necessarily reflect the official position of the American Society of Agricultural and Biological Engineers (ASABE), and its printing and distribution does not constitute an endorsement of views which may be expressed. Technical presentations are not subject to the formal peer review process by ASABE editorial committees; therefore, they are not to be presented as refereed publications. Citation of this work should state that it is from an ASABE meeting paper. EXAMPLE: Author's Last Name, Initials. 2006. Title of Presentation. ASABE Paper No. 06xxxx. St. Joseph, Mich.: ASABE. For information about securing permission to reprint or reproduce a technical presentation, please contact ASABE at hq@asabe.org or 269-429-0300 (2950 Niles Road, St. Joseph, MI 49085-9659 USA). 


\section{Introduction}

Arid conditions and persistent winds, characteristic of much of the western United States provide a climate conducive to wind erosion. Fugitive dust generated from exposed soil at construction sites, post-wildfire areas, and agricultural fields is a widespread problem with both human health and environmental implications. In 1987 the U.S. Environmental Protection Agency (EPA) included particulate matter with a mean aerodynamic diameter equal to or less than $10 \mu \mathrm{m}\left(\mathrm{PM}_{10}\right)$ as one of the six criteria pollutants in the Clean Air Act. Since then, numerous epidemiological studies have shown a strong correlation between respiratory ailments, including asthma incidence, and $\mathrm{PM}_{10}$ (Koren, 1995; Peden, 2001). Based upon these findings, National Ambient Air Quality Standards have been set regulating $\mathrm{PM}_{10}$ on a 24-hour basis and $\mathrm{PM}_{2.5}$ on both a 24-hour and annual average basis (U.S. EPA, 40 CRF part 50).

Aside from the health issues directly related to particulate matter, $\mathrm{PM}_{10}$ also represents the most chemically active portion of the soil and, thus, has the potential to transport heavy metals, pesticides, and microbes. In addition to these potentially harmful compounds, $\mathrm{PM}_{10}$ may also transport nutrients necessary for plant growth, reducing productivity of agricultural soils (Shinn, 2000).

Impacts of particulate matter can be realized in areas distant from the actual dust source. Once the fine-sized particles are in suspension, they can remain in the atmosphere for long periods of time before being re-deposited. For instance, dust storms in the Columbia Plateau region of the Pacific Northwest have been shown to affect air quality in eastern Washington and the Idaho Panhandle, with ambient $\mathrm{PM}_{10}$ concentrations exceeding air quality standards numerous times since monitoring began in 1985 (Saxton et al., 1995; Sharratt and Lauer, 2006). Influx of dust originating from events as far away as Asia has been measured on the Columbia Plateau (Vaughan et al., 2001).

The three types of soil movement associated with wind erosion are saltation, suspension, and surface creep. Particle transport via suspension is considered to be the dominant erosive mechanism for fine textured soils such as the one used in this study (Saxton, 1999; Chandler and Saxton, 2001; Sharratt et al., 2006). When considered together, saltation and suspension are referred to as the total suspended sediment. A common model for estimating soil loss from wind erosion is (Woodruff and Siddoway, 1965)

$$
E=f(I, K, C, L, V)
$$

where $E=$ estimated average annual soil loss,

$$
\begin{aligned}
& I=\text { soil erodibility index, } \\
& K=\text { ridge roughness factor, } \\
& C=\text { climate factor, } \\
& L=\text { unsheltered length of eroding land, } \\
& V=\text { vegetative cover factor. }
\end{aligned}
$$

Typically wind erosion is controlled by increasing vegetative cover, increasing surface roughness, decreasing unsheltered length (sometimes referred to as fetch length), or a combination of the three. Traditional management practices have included implementation of 
wind breaks, shelterbelts, soil moisture management techniques, and conservation tillage practices on agricultural lands. Newer approaches have also included the application of soil binding agents and stabilizers, such as polyacrylamides (Armbrust, 1999).

Perhaps the most widely used material for erosion control has been agricultural straw. It has been commonly used for water erosion control; however, it has been less effective in controlling wind erosion, as it is a light-weight material and lacks stability during high wind events. Other drawbacks to the use of straw arise when application is considered on wildlands or in forested settings. One of these drawbacks is the concern over the introduction of noxious weeds and non-native species to forested areas (Robichaud et al., 2000). Straw itself carries fine dust particles which may be liberated when the straw elements are shattered, posing a health hazard to workers involved in the spreading (Kullman et al., 2002). Furthermore, when left in the field, straw has agronomic and ecological value. Straw is also a raw material for other potentially high value uses such as energy production (Gorzell, 2001). Value-added products derived from straw may reduce the supply for erosion control.

Forest Concepts, LLC, a Washington-based company, has been developing a wood analog to the agricultural straw made from the by-products of forest thinning and plywood manufacturing. The wood-strand materials (WoodStraw ${ }^{\mathrm{TM}}$ ) are heavier than straw, and thus, less likely to be blown away when exposed to high winds. Wood strands also have favorable mulching characteristics for decomposing into environment-friendly biomass, offer long-term resistance to erosion, and do not introduce noxious weeds, pesticides, or non-native materials to wildlands (Foltz and Dooley 2003). In addition, the manufacturing of wood strands will utilize what were previously considered waste materials. The use of wood strands as an alternative material for water erosion control has already been investigated. Studies conducted by Foltz and Dooley (2003) and Yanosek et al. (2006) reported that agricultural straw and wood strands were equally effective on two soil types in reducing erosion by over $98 \%$ when compared to a bare soil.

The current study was intended to identify important dimensional characteristics of wood strands for wind erosion control. Through a series of wind tunnel tests, the impacts of selected material properties and application strategies were evaluated. The study had two goals (1) to compare the effectiveness of wood strands and agricultural straw in reducing soil loss and maintaining air quality and (2) to identify dimensional characteristics impacting the erosion reduction efficacy of the wood strands.

\section{Materials and Methods}

Wind tunnel experiments were performed at the U.S. Department of Agriculture-Agricultural Research Service (USDA-ARS) Palouse Conservation Field Station in Pullman, Washington. The experiments were carried out in a non-regulated climate facility using a portable wind tunnel (Pietersma et al., 1996) with a working section $1.0 \mathrm{~m}$ wide, $1.2 \mathrm{~m}$ tall, and $7.3 \mathrm{~m}$ long. Wind was generated by a 1.4-m diameter Joy Series 1000 axivane fan driven by a Ford industrial type gas engine. Thirteen available engine speeds and variable pitch fan blades yield free stream velocities in the range of $<2$ to $20 \mathrm{~m} / \mathrm{s}$. A bell infuser and curvilinear guiding vanes were employed to ensure smooth, efficient transitions at the upwind and downwind edges of the fan, respectively. The flow was passed through a diffuser and honeycomb-screen combination to reduce turbulence. Sand-coated (for fixed surface roughness) plywood was used for the floor of the tunnel. This allowed for establishment and stabilization of the boundary layer upwind of the test surface.

The experiment was a completely randomized design with 11 different treatment combinations of coverage elements and amounts. Each treatment combination was replicated four times. Surface treatments included a bare soil, a soil covered with air-dried wheat straw at either 50 or 
$70 \%$ cover, and a soil covered with air-dried wood strands of varying dimensions at either 50 or $70 \%$ cover as shown in Table 1. Treatments of wood strands included long strands at two thicknesses and a mixture of short and long strands at two thicknesses. Blends were created on a 50:50 mass basis (long and short at designated thickness). All wood strands had a standard width of $4.5 \mathrm{~mm}$. The wood strands used in this experiment were produced from Douglas fir clear wood blocks.

This paper will only discuss results from the bare soil, straw at $70 \%$ cover, and mixed thick wood strands at $70 \%$ cover. The treatment combinations for straw and wood straw discussed in this paper are representative of the results for all straw and wood strand treatments.

Table 1. Treatment combinations.

\begin{tabular}{lcc}
\hline Cover & \% Cover & Dimensions \\
\hline Bare & 0 & - \\
\hline \multirow{2}{*}{ Agricultural Straw } & 50 & - \\
\hline & 70 & - \\
\hline Wood Strands & 50 & Long/Thick \\
& & Mix/Thick \\
& & Long/Thin \\
& & Mix/Thin \\
\cline { 2 - 3 } & & Long/Thick \\
& 70 & Mix/Thick \\
& & Long/Thin \\
& & Mix/Thin \\
\hline
\end{tabular}

* Long: $240 \mathrm{~mm}$ in length, short: $64 \mathrm{~mm}$ in length, thick: $4.8 \mathrm{~mm}$ in thickness, thin: $2.5 \mathrm{~mm}$ in thickness.

Ambient temperature and relative humidity were monitored during testing, as these parameters affect particle suspension. In addition, soil matric potential was measured prior to each wind tunnel run and a bare soil was included in the treatments examined each day for controlling experimental error.

A Ritzville silt loam soil (coarse-silty, mixed, superactive, mesic Calcidic Haploxeroll) collected from the Columbia Plateau near Ritzville, Washington was selected for the study due to its high potential to erode and emit $\mathrm{PM}_{10}$ (Chandler et al., 2004). Prior to testing, the soil was air dried and sieved to remove particle sizes larger than $2 \mathrm{~mm}$ in diameter. Non-dispersed particle size analysis indicated that over $70 \%$ of the soil size fraction $(<2 \mathrm{~mm}$ size fraction) was comprised of $\mathrm{PM}_{100}$ (particulate matter $\leq 100 \mu \mathrm{m}$ in diameter) with nearly $4 \%$ as $\mathrm{PM}_{10}$. Aluminum trays 1.00 $\mathrm{m}$ long, $0.50 \mathrm{~m}$ wide, and $0.04 \mathrm{~m}$ deep were constructed to hold the soil during testing. Trays 
were filled in three layers. After the addition of each soil layer, the sides of the trays were tapped to ensure even settling. Following the addition of the third layer, the trays were overfilled with soil and then leveled with a screed. Cutouts were made in the plywood floor $(5.0 \mathrm{~m}$ downstream from fan) to allow for placement of the trays such that the soil surface was flush with the tunnel floor.

Cover treatments were applied by hand prior to transfer to the tunnel. Vertical pictures of the trays were taken before and after each run and actual percent cover for each tray was determined by a point count using a 48-point grid overlay. Average cover height was also measured prior to each run. Testing was performed with free stream velocities of 6.5 and 18 $\mathrm{m} / \mathrm{s}$ (15 and $40 \mathrm{mph}$ ). Each soil treatment was subjected to the wind for a duration of five minutes during which sediment loss and $\mathrm{PM}_{10}$ concentrations were measured.

Measurements made during testing included: (1) loss of total suspended sediment and surface creep to determine total sediment loss from the tray and (2) $\mathrm{PM}_{10}$ concentrations (a fraction of the suspended particles) to asses the impact on air quality. Total suspended sediment was measured using a vertically integrating isokinetic slot sampler (modified Bagnold type, Stetler et al., 1997) connected in series with a high efficiency cyclone and vacuum. A collection tray was attached to the downwind edge of the soil tray to catch surface creep. Summing the sediment mass caught by these two devices allows for calculation of the total sediment loss from the tray.

$\mathrm{PM}_{10}$ concentrations were measured using TSI DustTrak ${ }^{\mathrm{TM}}$ Aerosol Monitors (TSI, Inc., St. Paul, Minnesota). The DustTrak ${ }^{\mathrm{TM}}$ is a high volume, constant flow portable laser photometer capable of measuring particle sizes in the range of 0.1 to $10 \mu \mathrm{m}$. Aerosol inlets were placed at $0.5,1.0$, 2.0 and $4.0 \mathrm{~cm}$ above the cover surface at the downstream edge of the soil tray. Background $\mathrm{PM}_{10}$ concentrations were monitored with two additional aerosol monitors located at the upstream end of the tunnel. Wind speeds were measured at heights corresponding to the DustTrak inlet heights using pitot tubes connected to differential pressure transmitters (Series 606, Dwyer Instruments, Inc., Michigan City, Indiana). Free stream velocity was measured with an additional pitot tube at a height of $1.0 \mathrm{~m}$ inside the wind tunnel.

\section{Results and Discussion}

Results are reported here for straw at $70 \%$ cover and mixed, thick wood strands at $70 \%$ cover. $\mathrm{PM}_{10}$ concentration for all treatments diminished with time over the 5 minutes of testing. The trends in $\mathrm{PM}_{10}$ concentration over time (Figures 1 and 2) were similar to the conceptual trend reported in Loosemore and Hunt (2000) for nonabraded dust resuspension. $\mathrm{PM}_{10}$ emissions are reported only for the first 60 seconds of testing, as the concentrations reached background $\mathrm{PM}_{10}$ concentrations in the atmosphere within this time period. Total sediment loss is reported for the entire 5 minute testing period.

\section{$6.5 \mathrm{~m} / \mathrm{s}$ wind velocity}

Wood strands remained intact at the soil surface at a free stream velocity of $6.5 \mathrm{~m} / \mathrm{s}$. Although most of the straw remained on the plot, there was mass movement of straw from the upwind edge to the middle of the tray during the first few seconds of testing. However, the straw became intertwined and re-stabilized, resulting in little loss of straw elements from the tray. Overall, total sediment loss was low for the $6.5 \mathrm{~m} / \mathrm{s}$ wind velocity, with total sediment loss for all treatments being approximately $2 \mathrm{~g} / \mathrm{m}^{2}$ (Table 2 ). A one-way analysis of variance indicated that there was no significant difference in total sediment loss due to treatment type ( $p$-value $=$ $0.9121)$. 
Although there was no significant difference in total sediment loss among treatments at the 6.5 $\mathrm{m} / \mathrm{s}$ wind velocity, there was a notable difference in the peak $\mathrm{PM}_{10}$ concentrations. Peak concentrations from the bare soil were approximately $10 \mathrm{mg} / \mathrm{m}^{3}$. The straw was effective in reducing $\mathrm{PM}_{10}$ peak concentrations to approximately $2 \mathrm{mg} / \mathrm{m}^{3}$. The wood strands reduced emissions even further, with peak concentrations under $0.5 \mathrm{mg} / \mathrm{m}^{3}$. Since $P M_{10}$ is a fraction of the total suspended sediment, one would expect $\mathrm{PM}_{10}$ loss and total suspended sediment to be correlated. The resolution of the scales used may have contributed to difficulties in detecting differences among total sediment loss, as the total mass lost from trays at this wind speed was on the order of one resolutional unit.

\section{$18 \mathrm{~m} / \mathrm{s}$ wind velocity}

The wood strands remained intact on the soil surface at a free stream velocity of $18 \mathrm{~m} / \mathrm{s}$. In contrast, the straw was completely blown from the test trays within the first few seconds of the run. Overall soil loss was much greater at this test velocity, with losses near $130 \mathrm{~g} / \mathrm{m}^{2}$ from the bare and straw treatments (Table 2). Wood strands reduced the average total sediment loss by a factor of 10 when compared to the bare plot. Interestingly, average sediment loss from the straw treatment was greater than that from the bare plot. This is likely because as the straw was blown from the tray, it scoured the soil surface, carrying soil particles with it. This was reflected in the results of the creep portion of the total sediment loss (Table 2); the mass transported via creep from the straw treatment was nearly twice that from the bare treatment.

A one-way analysis of variance was performed on the data after one outlier was removed. Results indicated that at this wind speed there was a statistically significant difference in total sediment loss due to treatment ( $p$-value $<0.0001)$. Tukey's method of multiple pairwise comparisons grouped the total sediment loss from the bare and straw treatments into a class which was significantly different from the wood strands treatment. Therefore, it can be concluded that total sediment loss from the bare was not significantly different than that from the straw, but the sediment loss from the wood strands was significantly lower than that from the bare and the straw treatments.

Although there was no difference in total sediment loss between the bare and straw treatments, Tukey's procedure indicated that there was a significant difference in creep at the alpha $=0.05$ level ( $p$-value $=0.0496$ ). So, the amount of soil transported as creep from the straw treatments was significantly larger than that from the bare treatments. This supports the theory of soil particle mobilization due to straw elements as the straw was blown from the plot.

$\mathrm{PM}_{10}$ emissions were considerably higher for all treatments during the $18 \mathrm{~m} / \mathrm{s}$ testing. Peak emissions from the bare soil were above $250 \mathrm{mg} / \mathrm{m}^{3}$. Peaks from the straw treatment were nearly as high as those from the bare soil, typically near $200 \mathrm{mg} / \mathrm{m}^{3}$; this is reasonable considering the straw was completely blown from the plot within the first few seconds of testing. Emissions from the wood strand treatment were notably lower, with peaks typically under 25 $\mathrm{mg} / \mathrm{m}^{3}$. 
Table 2. Average total sediment loss for each treatment

\begin{tabular}{|c|c|c|c|c|c|c|}
\hline & \multicolumn{3}{|c|}{$6.5 \mathrm{~m} / \mathrm{s}$} & \multicolumn{3}{|c|}{$18 \mathrm{~m} / \mathrm{s}$} \\
\hline & $\begin{array}{c}\text { Bare } \\
\left(\mathrm{g} / \mathrm{m}^{2}\right)\end{array}$ & $\begin{array}{c}\text { Agricultural } \\
\text { Straw } \\
\left(\mathrm{g} / \mathrm{m}^{2}\right) \\
\end{array}$ & $\begin{array}{c}\text { Wood } \\
\text { Strands } \\
\left(\mathrm{g} / \mathrm{m}^{2}\right)\end{array}$ & $\begin{array}{c}\text { Bare } \\
\left(\mathrm{g} / \mathrm{m}^{2}\right)\end{array}$ & $\begin{array}{c}\text { Agricultural } \\
\text { Straw } \\
\left(\mathrm{g} / \mathrm{m}^{2}\right)\end{array}$ & $\begin{array}{c}\text { Wood } \\
\text { Strands } \\
\left(\mathrm{g} / \mathrm{m}^{2}\right)\end{array}$ \\
\hline Saltation/Suspension & 1.95 & 2.36 & 2.17 & 123.94 & 125.61 & 13.43 \\
\hline Creep & $0.01^{a}$ & $0.01^{a}$ & $0.02^{a}$ & $2.82^{\mathrm{b}}$ & $6.22^{c}$ & $0.18^{d}$ \\
\hline Total & $1.96^{a}$ & $2.37^{\mathrm{a}}$ & $2.19^{a}$ & $126.76^{b}$ & $131.83^{b}$ & $13.61^{\mathrm{c}}$ \\
\hline
\end{tabular}

${ }^{*} a, b, c$, and $d$ superscripts indicate groupings of significant mean values within a sediment loss category.

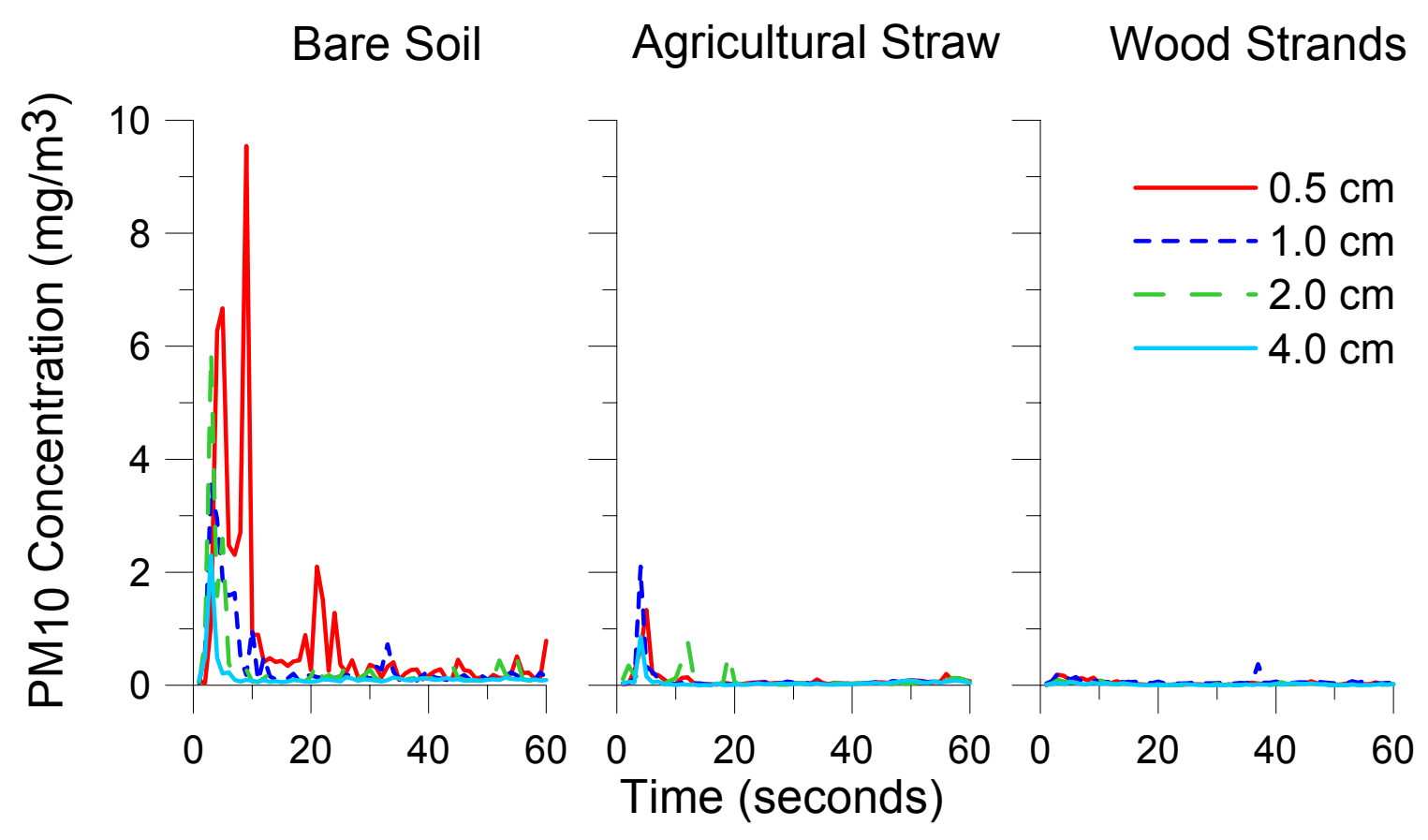

Figure 1. $\mathrm{PM}_{10}$ concentration over time for a free stream velocity of $6.5 \mathrm{~m} / \mathrm{s}$ 


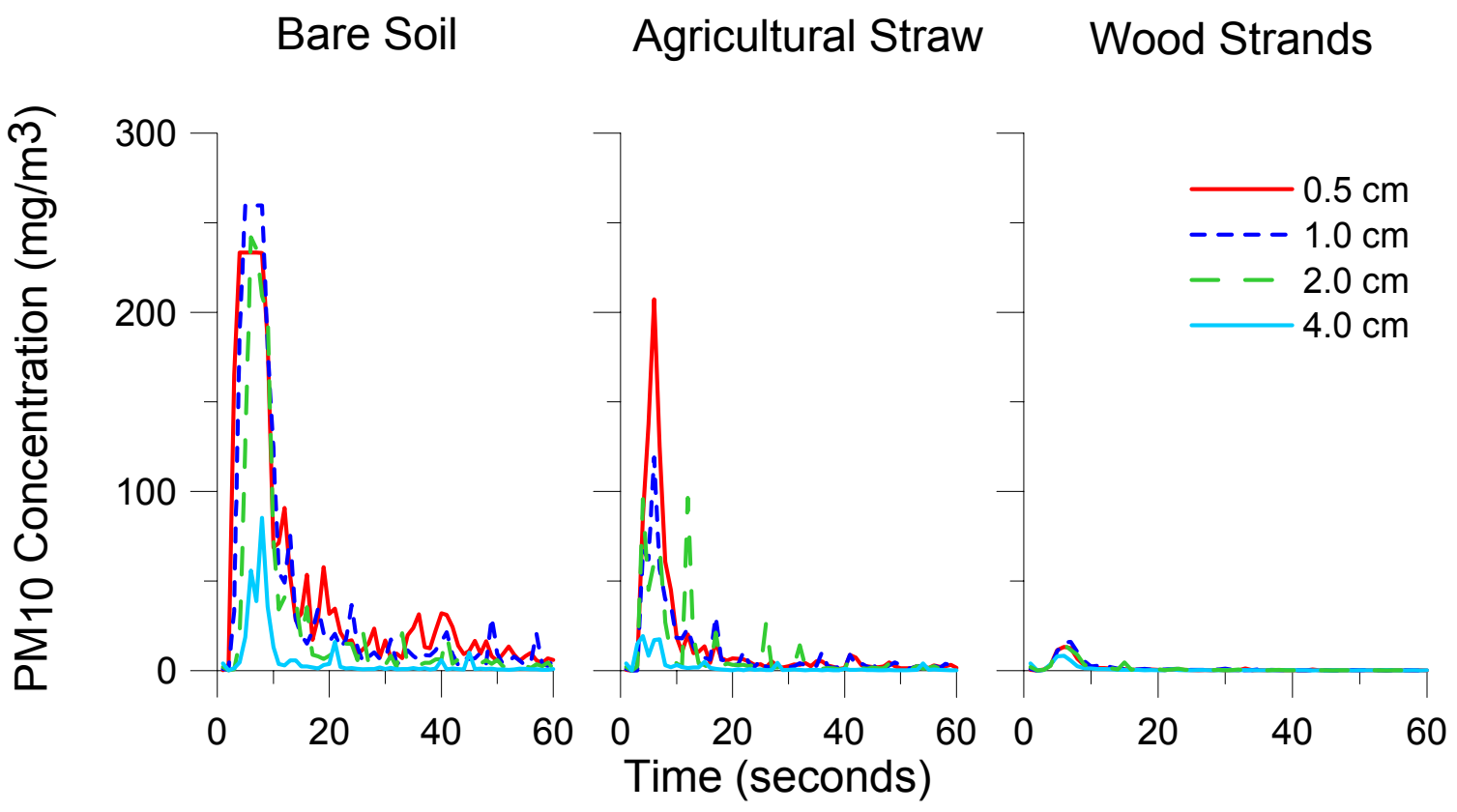

Figure 2. $\mathrm{PM}_{10}$ concentration over time for a free stream velocity of $18 \mathrm{~m} / \mathrm{s}$.

\section{Conclusion}

Wood strands were stable at wind speeds of up to $18 \mathrm{~m} / \mathrm{s}$. They were effective in reducing $\mathrm{PM}_{10}$ concentrations by over $90 \%$ compared to a bare soil at wind speeds of 6.5 and $18 \mathrm{~m} / \mathrm{s}$. Agricultural straw was not stable at wind speeds greater than $6.5 \mathrm{~m} / \mathrm{s}$, and at $18 \mathrm{~m} / \mathrm{s}$, the straw treatments had a higher average total sediment loss than the bare soil. Although the majority of the straw remained on the plots during the $6.5 \mathrm{~m} / \mathrm{s}$ runs, it did not demonstrate a high degree of stability, as there was mass movement from the upwind edge of the trays during the runs. These tests suggest that wood strands may be a viable alternative to agricultural straw in terms of wind erosion mitigation, as they are more stable at higher wind speeds and are capable of reducing total sediment loss and $\mathrm{PM}_{10}$ concentrations both by over $90 \%$ when compared to a bare soil. Further research in the field may provide more information in regards to comparison of the erosion reduction efficacy between the wood strands and agricultural straw, as microtopography will play a role in the performance of cover elements in the field.

\section{References}

Armbrust, D.V.. 1999. Effectiveness of polyacrylamide (PAM) for wind erosion control. J. Soil Water Conserv. 54: 557-559.

Chandler, D. and K.E. Saxton. 2001. Developments in measurements and models for suspension-dominated wind erosion. Sustaining the Global Farm. Selected paper from $10^{\text {th }}$ International Soil Conservation Organization Meeting held May 24-29 1999 at Purdue University and the USDA-ARS National Soil Erosion Research Laboratory.

Chandler, D., S. Blaesing-thompson, and A. Busacca. 2004. Geospatial assessment of agricultural lands critical to air quality on the Columbia Plateau, Washington State. J. Soil Water Conserv. 59: 184-189.

Foltz, R.B. and J.H. Dooley. 2003. Comparison of erosion reduction between wood strands and agricultural straw. Trans. ASAE 46(5): 1389-1396. 
Gorzell, K.E. 2001. Finding an economic and environmental balance to the technology of producing building materials from agricultural crop residue. ASAE Paper No. 016075. St. Joseph, Mich.: ASAE.

Koren, H. S. 1995. Associations between criteria air pollutants and asthma. Environ. Health Perspect. 103: 235-42.

Kullman, G., C. Piacitelli, J. Parker, J. Flesch, and J. May. 2002 Control of organic dusts from bedding choppers in dairy barns. NIOSH Publication No. 97-103. Washington, W.C.: National Institute of Safety and Health.

Loosemore, G. A. and J. R. Hunt. 2000. Dust resuspension without saltation. J. Geophys. Res. 105: 20663-20671.

Peden, D. B. 2001. Air pollution in asthma: effects of pollutants on airway inflammation. Ann. Allergy, Asthma Immunol. 87: 12-17.

Pietersma, D., L.D. Stetler, K.E. Saxton. 1996. Design and aerodynamics of a portable wind tunnel for soil erosion and fugitive dust research. Trans. ASAE. 39(6): 2075-2083.

Robichaud, P.R., J.L. Beyers, and D.G. Neary. 2000. Evaluating the effectiveness of postfire rehabilitation treatments. General Technical Report RMRS-GTR-63. Fort Collins, Colo.: USDA Forest Service, Rocky Mountain Research Station.

Saxton, K.E. 1995. Wind erosion and its impact on off-site air quality in the Columbia Plateau An integrated research plan. Trans. ASAE. 38(4): 1031-1038.

Saxton, K.E. 1999. Wind erosion and $\mathrm{PM}_{10}$ fluxes from agricultural fields on the Columbia Plateau. 1999 Annual Report. Northwest Columbia Plateau Wind Erosion/Air Quality Project. Agricultural Research Service, USDA, and Washington State University , Pullman, Wash. p. 7-9.

Sharratt, B., G. Feng, and L. Wendling. 2006. Loss of soil and PM10 from agricultural fields associated with high winds on the Columbia Plateau. Earth Surf. Process. Landforms DOI: 10.1002/esp.1425 (in press).

Sharratt, B., and D. Lauer. 2006 PMcoarse concentration and air quality affected by windblown dust in the Columbia Plateau. J. Environ. Quality DOI:10.21134/jeq2006.0212 (in press).

Shinn, E. A. 2000. African dust causes widespread environmental disaster. United States Geologic Survey Information sheet. St. Petersburg, FL. USGS Center for Coastal Geology.

Stetler, L., K. E. Saxton, and L. Horning. 1997. Isokinetic sampling of eroded soil from a wind tunnel. ASAE Pap. No. 97-2031. St. Joseph, Mich.: ASAE.

U.S. EPA. 2006. 40 CRF part 50. 222-267. Available at: http://www.epa.gov/oar/ particlepollution/pdfs/20060921_rule.pdf. Accessed on 4 October 2006.

Vaughan, J.K., C. Claiborn, and D. Finn. 2001. April 1998 Asian dust event over the Columbia Plateau. J. Geophys. Res. 106: 18381-18402.

Woodruff, N.P. and F.H. Siddoway. 1965. A wind erosion equation: Soil Sci. Soc. Am. Proc. 29(5): 602-608.

Yanosek, K.A., R.B. Foltz, and J.H. Dooley. 2006. Performance assessment of wood strand erosion control materials among varying slopes, soil textures and cover amounts. J.Soil Water Conserv.61(2): 45-51. 